\title{
Effects of Annealing Parameters on the Microstructure of Galvannealed Coating on DP590 Steel
}

\author{
Feng Huang ${ }^{1,2, *}$, Yu Chen ${ }^{2}$, Lin Hua ${ }^{1}$, Fang Fang ${ }^{2}$, Zhou Wang ${ }^{1}$ and Zhili $\mathrm{Hu}^{1}$ \\ ${ }^{1}$ School of Automotive Engineering, Wuhan University of Technology, Wuhan, 430070, China \\ ${ }^{2}$ Research and Development Center, Wuhan Iron and Steel Co., Wuhan, 430080, China \\ *Corresponding author
}

\begin{abstract}
Galvannealed coated sheet steels are extensively used in the automotive industry due to its good corrosion resistance, excellent spot weldability and paintability. However, galvannealed coated sheet steels generally present different forming behaviors, which mainly depend on the amount, orientation and distribution of different $\mathrm{Fe}-\mathrm{Zn}$ intermetallic phases in the coating. This paper deals with the characterizations of experimentally produced galvannealed coatings using Scanning Electron Microscope (SEM), Energy Dispersive Spectroscopy (EDS) and Glow Discharge Optical Emission Spectroscopy (GDOES). The effects of annealing parameters on the microstructure of galvannealed coating on DP590 steel were discussed. As a result, the proper annealing temperature and time for this dual phase steel are put forward.
\end{abstract}

Keywords-Galvannealed coating; microstructure; annealing parameter; dual phase steel

\section{INTRODUCTION}

Among the zinc- and zinc alloy-coated steels used in automotive bodies, galvannealed (GA) sheets are the most widely accepted due to their superior corrosion resistance, spot weldability and paintability, especially in the Japanese and Korean brands [1]. During the heat treatment after hot-dip galvanizing, the zinc in the galvanized coating will interdiffuse with the iron in the substrate, and then Fe-Zn intermetallics such as gamma $(\Gamma)$, gamma ${ }_{1}\left(\Gamma_{1}\right)$, delta $\left(\delta_{1 \mathrm{k}}\right.$ and $\delta_{1 \mathrm{p}}$ ) and zeta $(\zeta)$ are formed. Resulting from the presence of these hard brittle Fe-Zn intermetallics, the galvannealed coating always shows poor formability [2]. Since some new manufacturing systems such as highly automated press forming, welding and painting lines are introduced to the automotive industry, the quality of the galvannealed coating becomes more and more critical. Furthermore, as a result of the increasingly stringent requirements of the consumers and the growing competition, further improvement in forming behavior and appearance are essentially needed [3].

In fact, several efforts have been made to correlate the microstructure of the galvannealed coatings to their formability [4]. Some achievements have been obtained and many conclusions have been put forward: such as the $\Gamma$ phase at the interface is detrimental to the adhesion between the coating and substrate, the presence of $\zeta$ phase is beneficial for reducing powdering behavior [5], the formability of galvanealed coating decreases with the increasing of its iron content and the proper content is about $10 \mathrm{wt} \%$ [6]. At present, the published papers are mainly focused on the characterizations of the coatings and the correlation between their microstructure and properties. The microstructure evolution characteristics during the galvannealing process are rarely reported. The objective of this paper is to characterize the experimentally produced galvannealed coating and to discuss the effects of annealing parameters on its microstructure.

\section{EXPERIMENTAL METHODS}

The bare substrates were cut from cold rolled sheet as 110 $\mathrm{mm} \times 220 \mathrm{~mm}$ panels with the longitudinal direction of the samples paralleling to the rolling direction. The thickness of the substrate is $1.6 \mathrm{~mm}$ and the main alloying elements contents in this DP590 steel is shown in Table 1. The galvannealing experiments were conducted on a Hot Dip Process Simulator in Wuhan Iron and Steel Co. The steel panels were heated up to $790^{\circ} \mathrm{C}$ at $5 \mathrm{~K} / \mathrm{s}$, holding at this temperature for $60 \mathrm{~s}$, subjected to a fasting cooling of $15 \mathrm{~K} / \mathrm{s}$ down to $470^{\circ} \mathrm{C}$, dipped in a zinc bath with the temperature of $460^{\circ} \mathrm{C}$ for $3 \mathrm{~s}$, and then annealed to form Fe-Zn intermetallics. The whole galvannealing process was conducted under the following atmosphere: the dew point is $30^{\circ} \mathrm{C}$ and the $\mathrm{H}_{2}$ content of $\mathrm{H}_{2}-\mathrm{N}_{2}$ in volume is $5 \%$. For analyzing the effects of annealing parameters on the microstructure of galvannealed coating, six annealing conditions were used, as shown in Table 2. The galvannealed coatings under the galvanizing lines were characterized by SEM, EDS and GDOES.

\section{TABLE I. THE MAIN ALLOYING ELEMENTS CONTENTS IN DP590 SUBSTRATE (WT\%)}

\begin{tabular}{cccccc}
\hline C & Mn & Si & Als & Cr & Mo \\
\hline 0.0977 & 1.714 & 0.0167 & 0.0504 & 0.241 & 0.131 \\
\hline
\end{tabular}

\section{TABLE II. EXPERIMENTAL PARAMETERS}

\begin{tabular}{ccccccc}
\hline Serial number & 1 & 2 & 3 & 4 & 5 & 6 \\
\hline $\begin{array}{c}\left.\text { Annealing temperature [ }{ }^{\circ} \mathrm{C}\right] \\
\text { Annealing time [s] }\end{array}$ & 480 & 480 & 480 & 480 & 500 & 520 \\
\hline
\end{tabular}




\section{RESULTS AND DISCUSSION}

\section{A. Characterization of the Galvannealed Coating}

The typical surface morphologies of the coated samples are shown in Figure 1. As the concentrations of alloying elements such as Si and $\mathrm{Cr}$ are low, this dual phase steel shows good coatability, reflected by no bare spot is observed in the coating area. Since the bare substrates are cut from the cold rolled sheet, the residual stress will obviously be released

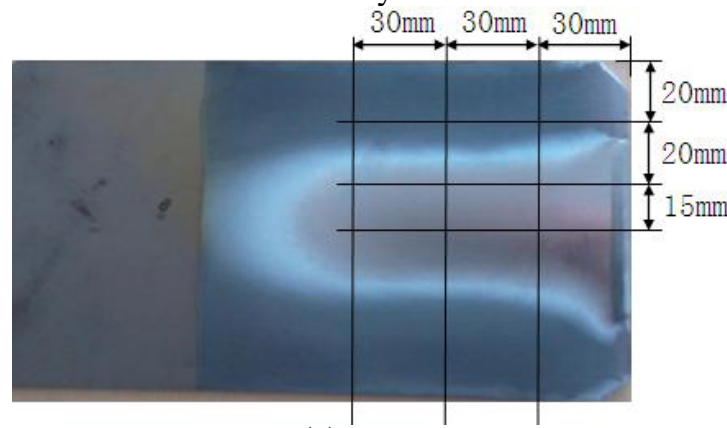

(a) during the galvannealing process, resulting in the bending of the samples. In this paper, the convex surface is defined as front and the concave surface is defined as back. In addition, the interdiffusion of $\mathrm{Zn}$ and $\mathrm{Fe}$ is inhomogeneous in the galvannealed coating area, reflected by different colors in different areas. As can be seen from the figure, the interdiffusion is obviously sufficient in the periphery and insufficient in the center along the longitudinal direction.

FIGURE I.

THE FRONT (A) AND BACK (B)

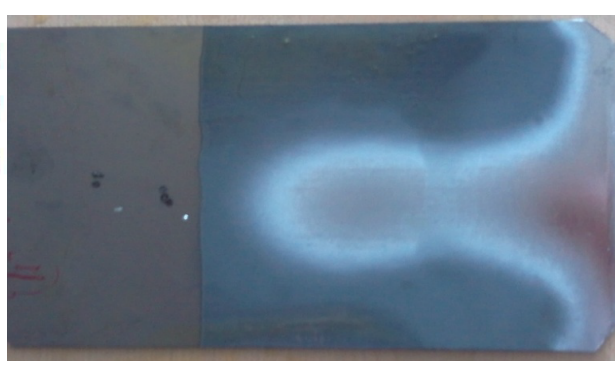

(b)
As shown in Figure 1(a), the thicknesses of the coating in the intersection points of the vertical and horizontal lines were measured by Fischer coating thickness gauge. The measurement results are shown in Table 3 . It is clear that, no matter at which height (30 mm, $60 \mathrm{~mm}$ or $90 \mathrm{~mm}$ ), the coating thickness increases from the periphery to the center. Combining the thickness measurement results, the surface morphologies shown in Figure 1 and discussions above, it is can be concluded that the inhomogeneous interdiffusion is probably caused by the substrate bending and different coating thickness. For improving the reliability in analyzing the effects of annealing parameters, all the characterization samples discussed below are cut from the peripheral area (20 $\mathrm{mm}$ from the side) of the corresponding galvannealed sheet.

\section{B. Effect of Annealing Temperature}

Figure 2 shows the SEM images of the coating surfaces annealed at different temperatures for 11s. As the figure showing, after annealed at $480{ }^{\circ} \mathrm{C}$, the coating surface is composed of a lot of blocky-shaped particles, a certain amount of trivial small particles and a small amount of rod-shaped particles. As the annealing temperature increases to $500^{\circ} \mathrm{C}$, the rod-shaped particles are almost disappeared and the amount of trivial small particles increases. When the annealing temperature further increases to $520^{\circ} \mathrm{C}$, the amount of trivial small particles decreases and the size of blocky-shaped particles increases slightly. Combining the discussions reported in reference [7], it can be concluded that, accompanying with the increasing of annealing temperature, the structure of the coating surface evolves from the rod-shaped $\zeta$ to blocky-shaped $\delta_{1 \mathrm{p}}$, then to trivial small $\delta_{1 \mathrm{k}}$ and finally to blocky-shaped $\delta_{1 \mathrm{k}}$. In addition, as shown in the figure, the compactness of the coating surface decreases with the increasing of annealing temperature.

TABLE III. THICKNESS OF THE COATING $(\mu \mathrm{M})$

\begin{tabular}{|c|c|c|c|c|c|c|}
\hline \multirow{3}{*}{$\begin{array}{l}\text { Distance } \\
\text { from } \\
\text { bottom }\end{array}$} & \multicolumn{6}{|c|}{ Distance from side } \\
\hline & \multicolumn{3}{|c|}{ Front } & \multicolumn{3}{|c|}{ Back } \\
\hline & $20 \mathrm{~mm}$ & $40 \mathrm{~mm}$ & $55 \mathrm{~mm}$ & $20 \mathrm{~mm}$ & $40 \mathrm{~mm}$ & $55 \mathrm{~mm}$ \\
\hline $30 \mathrm{~mm}$ & 14.1 & 19 & 27.9 & 16.6 & 17.2 & 17 \\
\hline $30 \mathrm{~mm}$ & 14.7 & 17.9 & 22.2 & 15.4 & 15.5 & 16.9 \\
\hline $30 \mathrm{~mm}$ & 14.6 & 17.8 & 20.7 & 15.2 & 15.5 & 16.5 \\
\hline
\end{tabular}

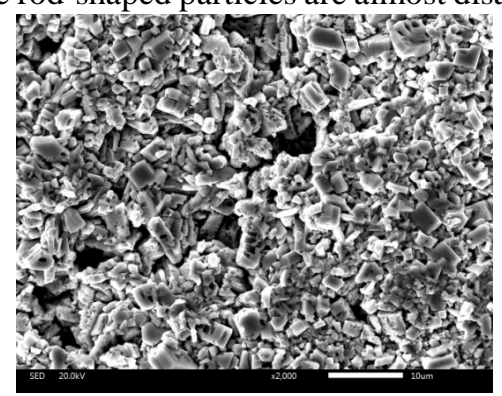

(a)

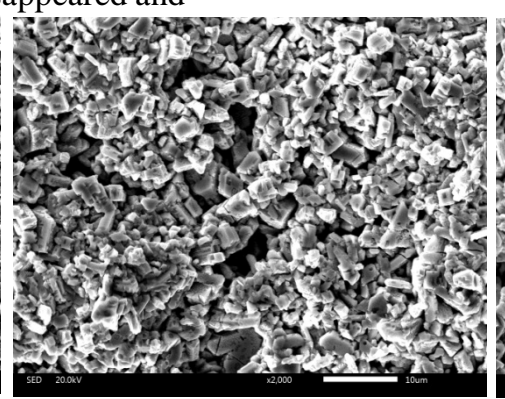

(b)

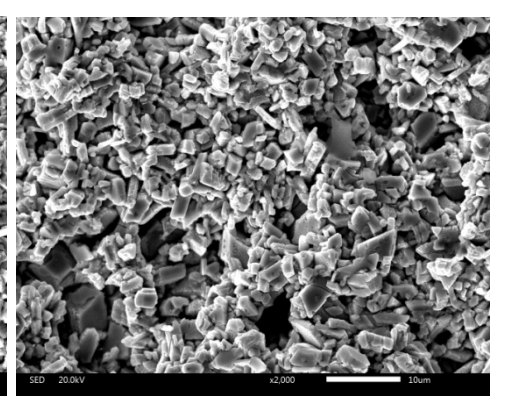

(c) 
The average iron contents near the interface, $1 / 4,1 / 2$ and 3/4 thickness of the coating detected by EDS are shown in Table 4. And according to the correlation between iron content and Fe-Zn intermetallics reported in reference [8], the corresponding structures are also listed in the table. As can be seen from the table, the average iron content in the coating decreases from the interface to the surface, accompanied by the structure changes from $\alpha \mathrm{Fe}$ to $\Gamma, \delta_{1 \mathrm{k}}, \delta_{1 \mathrm{p}}$ and $\zeta$, and the interdiffusion of $\mathrm{Zn}$ and $\mathrm{Fe}$ is speeded up while the annealing temperature is increased.

TABLE IV. THE EFFECT OF ANNEALING TEMPERATURE ON THE IRON CONTENT AND PHASE STRUCTURE IN THE COATING

\begin{tabular}{|c|c|c|c|c|c|c|c|c|}
\hline & \multicolumn{2}{|c|}{ Interface } & \multicolumn{2}{|c|}{ 1/4 Thickness } & \multicolumn{2}{|c|}{ 1/2 Thickness } & \multicolumn{2}{|c|}{ 3/4 Thickness } \\
\hline & $\mathrm{Fe} \%$ & Structure & $\mathrm{Fe} \%$ & Structure & $\mathrm{Fe} \%$ & Structure & $\mathrm{Fe} \%$ & Structure \\
\hline $480^{\circ} \mathrm{C}$ & 47.12 & $\alpha \mathrm{Fe}$ & 10.64 & $\delta_{1 \mathrm{p}}+\delta_{1 \mathrm{k}}$ & 8.55 & $\zeta+\delta_{1 \mathrm{p}}$ & 8.36 & $\zeta+\delta_{1 \mathrm{p}}$ \\
\hline $500{ }^{\circ} \mathrm{C}$ & 59.7 & $\alpha \mathrm{Fe}$ & 12.74 & $\delta_{1 \mathrm{p}}+\delta_{1 \mathrm{k}}$ & 9.73 & $\delta 1 \mathrm{p}+\delta_{1 \mathrm{k}}$ & 8.94 & $\zeta+\delta_{1 \mathrm{p}}$ \\
\hline $520^{\circ} \mathrm{C}$ & 52.25 & $\alpha \mathrm{Fe}$ & 14.46 & $\delta_{1 \mathrm{k}}$ & 11.35 & $\delta 1 \mathrm{p}+\delta_{1 \mathrm{k}}$ & 11 & $\delta 1 \mathrm{p}+\delta_{1 \mathrm{k}}$ \\
\hline
\end{tabular}

For describing the iron distribution in the coating more accurately, the GDOES measurements were employed. Figure 3 shows the iron concentration distribution profiles in the coatings annealed at different temperatures, and the corresponding structures in different iron concentration ranges are present. As the figure showing, the thickness of $\delta$ and $\zeta$ phase layer in the $520^{\circ} \mathrm{C}$ annealed coating is larger than that in the others while the thickness of $\Gamma$ phase layer is almost the same. Meanwhile, through comparing the slope of these three profiles, it can be found that the proportions of $\delta_{1 \mathrm{k}}$ and $\Gamma$ phase layers in the $520^{\circ} \mathrm{C}$ annealed coating is lower than that in the others. As $\delta_{1 \mathrm{k}}$ and $\Gamma$ are the most harmful phases which deteriorate the formability of the galvannealed coating seriously, then when the annealing time is set at $11 \mathrm{~s}$, the proper annealing temperature for this DP590 steel is $520^{\circ} \mathrm{C}$.

\section{Effect of Annealing Time}

Figure 4 shows the SEM images of coating surfaces annealed at $480^{\circ} \mathrm{C}$ for different times. The image for $11 \mathrm{~s}$ has been shown in Figure 2(a). As can be seen from the figure, the coating surface structure evolution characteristic is as same as that shown in Figure 2. The amount of trivial small $\delta_{1 \mathrm{k}}$ decreases with the extending of annealing time, and the size of

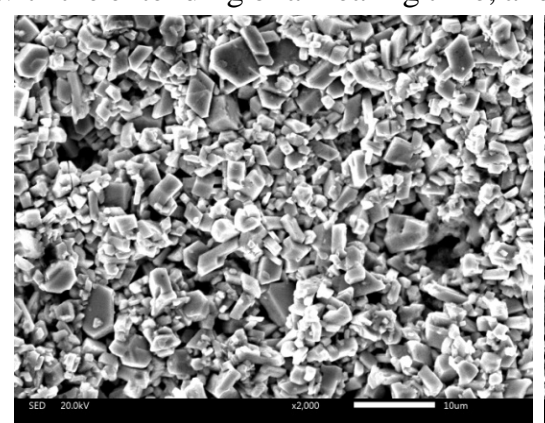

(a)

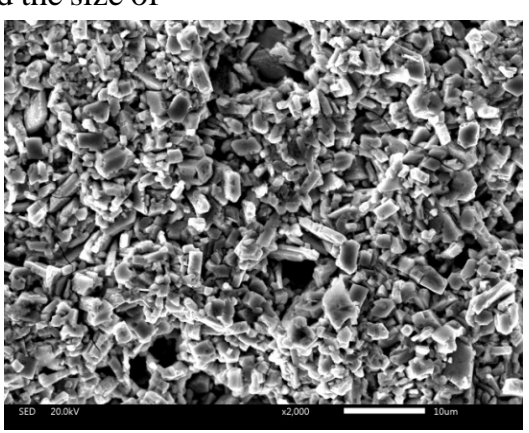

(b) blocky-shaped particles increases slightly. In addition, comparing the images with that shown in Figure 2, it is clear that, within the parameter range used in this paper, the effect of annealing time on the microstructure of the coating surface is slightly lower than that of annealing temperature.

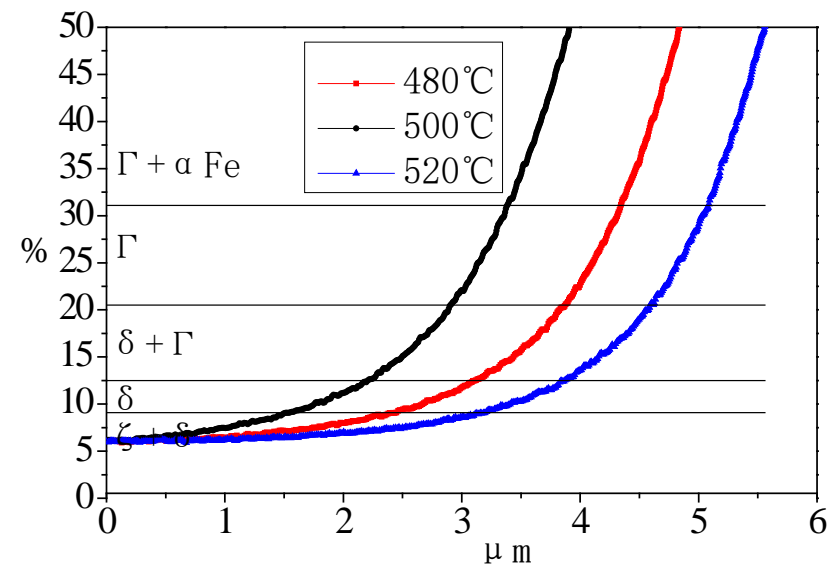

FIGURE III. THE IRON CONCENTRATION DISTRIBUTION PROFILES IN THE COATINGS ANNEALED AT DIFFERENT TEMPERATURES

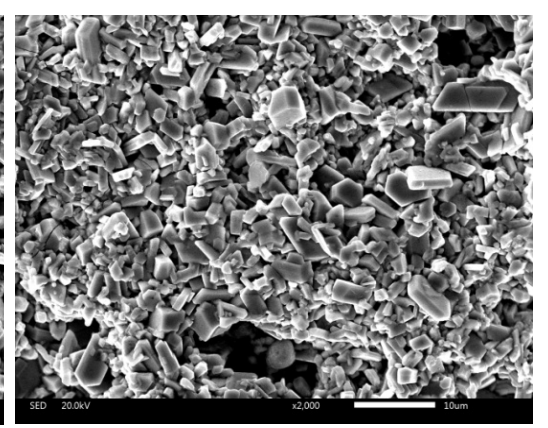

(c)

FIGURE IV. SEM IMAGES OF COATING SURFACE ANNEALED AT 480 C FOR DIFFERENT TIMES (A)7S; (B)16S; (C)20S

The average iron contents detected by EDS and the corresponding structure in different regions of the coatings annealed at $480^{\circ} \mathrm{C}$ for different times are shown in Table 5 . The same as that shown in Table 4, the iron content in the coating decrease from the interface to the surface, and at the same region, such as near the interface, $1 / 4,1 / 2$ and $3 / 4$ thickness of the coating, the extending of annealing time results in the increasing of iron content. The abnormal data in 
some region such as $10.64 \%$ at $1 / 4$ thickness of the coating annealed for $11 \mathrm{~s}$ is probably caused by the improper

positioning of detected point.

TABLE V. THE EFFECT OF ANNEALING TIME ON THE IRON CONTENT AND PHASE STRUCTURE IN THE COATING

\begin{tabular}{|c|c|c|c|c|c|c|c|c|}
\hline & \multicolumn{2}{|c|}{ Interface } & \multicolumn{2}{|c|}{ 1/4 Thickness } & \multicolumn{2}{|c|}{ 1/2 Thickness } & \multicolumn{2}{|c|}{ 3/4 Thickness } \\
\hline & $\mathrm{Fe} \%$ & Structure & $\mathrm{Fe} \%$ & Structure & $\mathrm{Fe} \%$ & Structure & $\mathrm{Fe} \%$ & Structure \\
\hline $7 s$ & 34.34 & $\Gamma+\alpha \mathrm{Fe}$ & 13.71 & $\delta_{1 \mathrm{k}}$ & $9.48 \%$ & $\delta_{1 \mathrm{p}}+\delta_{1 \mathrm{k}}$ & 8.61 & $\delta_{1 \mathrm{p}}$ \\
\hline $11 \mathrm{~s}$ & 47.12 & $\alpha \mathrm{Fe}$ & 10.64 & $\delta_{1 \mathrm{p}}+\delta_{1 \mathrm{k}}$ & $8.55 \%$ & $\zeta+\delta_{1 \mathrm{p}}$ & 8.36 & $\zeta+\delta_{1 \mathrm{p}}$ \\
\hline $16 \mathrm{~s}$ & 51.7 & $\alpha \mathrm{Fe}$ & 12.41 & $\delta_{1 \mathrm{k}}$ & $10.39 \%$ & $\delta_{1 \mathrm{p}}+\delta_{1 \mathrm{k}}$ & 9.61 & $\delta_{1 \mathrm{p}}$ \\
\hline $20 \mathrm{~s}$ & 33.4 & $\Gamma+\alpha \mathrm{Fe}$ & 15.87 & $\delta_{1 \mathrm{k}}+\Gamma$ & 11.49 & $\delta_{1 \mathrm{p}}+\delta_{1 \mathrm{k}}$ & 10.3 & $\delta_{1 \mathrm{p}}+\delta_{1 \mathrm{k}}$ \\
\hline
\end{tabular}

Figure 5 shows the iron concentration distribution profiles in the coatings annealed for different times. It is clear that the slope of the profile for $16 \mathrm{~s}$ is lower than that for the other annealing times, especially in the lower iron concentration range, indicating the proportion of $\zeta$ phase layer is higher and $\delta_{1 \mathrm{k}}$ and $\Gamma$ phase layers are lower in this $16 \mathrm{~s}$ annealed coating. This is obviously beneficial for improving the formability of the galvannealed coating. Based on this, when the annealing temperature is set at $480^{\circ} \mathrm{C}$, the galvanized coating on this DP590 steel should better be annealed for $16 \mathrm{~s}$.

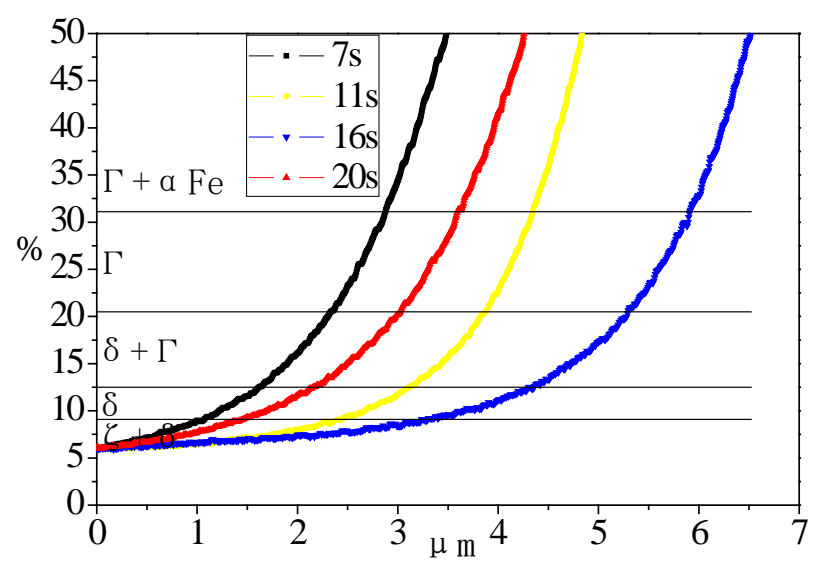

FIGURE V. THE IRON CONCENTRATION DISTRIBUTION PROFILES IN THE COATINGS ANNEALED FOR DIFFERENT TIMES

According to the discussions above, from the perspective of improving the forming behavior, the ideal annealing conditions for the galvanized coating on this DP590 steel are as following: annealed at $520^{\circ} \mathrm{C}$ for $11 \mathrm{~s}$ or annealed at $480^{\circ} \mathrm{C}$ for $16 \mathrm{~s}$. As compared with the latter, the former one is obviously beneficial for improving the production efficiency.

\section{Summary}

In this paper, the characterizations of the galvannealed coatings were measured and the effects of annealing parameters were discussed. The following conclusions can be made:

1) Resulting from the substrate bending and different coating thickness, the interdiffusion of $\mathrm{Zn}$ and $\mathrm{Fe}$ are inhomogeneous in the galvannealed coating area.

2) Increasing the annealing temperature or extending the annealing time will result in the microstructure of the coating surface evolves from rod-shaped $\zeta$ to blocky-shaped $\delta_{1 \mathrm{p}}$, then to trivial small $\delta_{1 \mathrm{k}}$ and finally to blocky-shaped $\delta_{1 \mathrm{k}}$, and the effect of temperature is slightly higher than that of time.

3) The iron content in the coating decreases from the interface to the surface and increases with the increasing of annealing temperature or extending of the annealing time.

4) For improving the formability and production efficiency, the galvanized coating on this DP590 steel should better be annealed at $520^{\circ} \mathrm{C}$ for $11 \mathrm{~s}$.

\section{ACKNOWLEDGEMENT}

This project was supported by State Key Laboratory of Material Processing and Die \& Mould Technology, Huazhong University of Science and Technology (P2016-06). The authors are thankful to Yanwen Zhang, Zhutao Xu and Jiangwen Li in Wuhan Iron and Steel Co., for supporting the coating characterization measurement.

\section{REFERENCES}

[1] Yun-II Choi, Eui-Sub Shin, Kensuke Kuroda, Masazumi Okido, Chan-Jin Park, "Improved surface morphology and corrosion resistance for galvannealed coatings by pre-electroplating iron," Corrosion Science, vol. 58, pp. 152-158, 2012.

[2] S.I.Kim, J.U.Her, Y.C.Jang, Y.Lee, "Experimental and finite element analysis for fracture of coating layer of galvannealed steel sheet," Trans. Nonferrous Met. Soc. China, vol. 21, pp. 111-116, 2011.

[3] Chakraborty, R.Saha, R.K.Ray, "Characterization of industrially produced galvannealed coating using cross-sectional specimen in TEM,” Materials Characterization, vol. 60, pp. 882-887.2009.

[4] Chakraborty, R.K.Ray, "Influence of microstructure and texture on the formability character of industrially produced galvannealed coatings on three interstitial free steels," Surface \& Coatings Technology, vol. 203, pp. 1756-1764, 2009.

[5] Norihiko L.Okamoto, Daisuke Kashioka, Masahiro Inomoto, Haruyuki Inui, Hiroshi Takebayashi, Shu Yamaguchi, "Compression deformability of $\Gamma$ and $\zeta$ Fe-Zn intermetallics to mitigate detachment of brittle intermetallic coating of galvannealed steels," Scripta Materialia, vol. 69, pp. 307-310, 2013.

[6] Xiaodong Hao, Qifu Zhang, "Influence of Fe Content on the Powdering Resistance and Corrosion Resistance of High Strength IF Galvannealed Coating," Corrosion \& Protection, vol. 29, pp. 736-737, 2008.

[7] L.G.Garza, C.J.Van Tyne, "Friction and formability of galvannealed interstitial free sheet steel," Journal of Materials Processing Technology, vol. 187-188, pp.164-168, 2007.

[8] Subhankar Das Bakshi, Monojit Dutta, N.Bandyopadhyay, N.Rajesh, "Improvement in galvannealed coating of IF-HS steel strips by combined GDOES and colour-etching method,” Surface \& Coating Technology, vol. 201, pp. 4547-4552, 2007. 